\title{
Retraction Note to: Sign-changing solutions to Schrödinger-Kirchhoff-type equations with critical exponent
}

Liping $\mathrm{Xu}^{1 *}$ and Haibo Chen ${ }^{2}$

"Correspondence: x.liping@126.com

'Department of Mathematics and Statistics, Henan University of

Science and Technology, Luoyang,

471003, P.R. China

Full list of author information is

available at the end of the article

\section{Retraction Note}

This article [1] has been retracted because it was republished in error [2]. The publisher apologizes to the authors and readers for the error and for any inconvenience caused.

Author details

'Department of Mathematics and Statistics, Henan University of Science and Technology, Luoyang, 471003, P.R. China.

${ }^{2}$ School of Mathematics and Statistics, Central South University, Changsha, 410075, P.R. China.

\section{Publisher's Note}

Springer Nature remains neutral with regard to jurisdictional claims in published maps and institutional affiliations.

Published online: 12 April 2017

\section{References}

1. Xu, L, Chen, H: Sign-changing solutions to Schrödinger-Kirchhoff-type equations with critical exponent. Adv. Differ. Equ. 2016, 176 (2016). doi:10.1186/s13662-016-0864-9

2. Xu, L, Chen, H: Sign-changing solutions to Schrödinger-Kirchhoff-type equations with critical exponent. Adv. Differ. Equ. 2016, 121 (2016). doi:10.1186/s13662-016-0828-0 